producing tract yet discovered. As to gold and silver, nothing trustworthy is known. Jade and amber are found in parts. But the most valuable of the Upper Burmah minerals is likely to be coal, of which there are certainly four fields, one of which has already yielded excellent fuel.

Dr. Holub, whose murder to the north of the Zambesi is doubtfully announced, may be remembered as the author of "Seven Years in South Africa," published about six years ago. He set out some three years ago to march from the Cape to Cairo, partly for purposes of exploration, and partly to open up markets in Central Africa for Austrian commerce. He does not seem to have made much speed.

Prof. Miguel Marazta has made what seems a curious anthropological discovery in the valley of Rebas (Gerona) at the end of the Eastern Pyrenees. There exists in this district a sonewhat numerous group of people, who are called Nanos (dwarfs) by the other inhabitants, and as a matter of fact are not more than four feet in height (I'IO to $I^{\prime} I_{5}$ metres). Their bodies are fairly well built, hands and feet small, shoulders and hips broad, making them appear more robust than they really are. Their features are so peculiar that there is no mistaking them among others. All have red hair; the face is as broad as long, with high cheek-bones, strongly developed jaws, and flat nose. The eyes are not horizontal but somewhat oblique, like those of Tartars and Chinese. A few straggling weak hairs are found in place of beard. The skin is pale and flabby. Men and women are so much alike that the sex can only be told from the clothing. Though the mouth is large, the lips do not quite cover the large projecting incisors. The Nanos, who are the butt of the other inhabitants, live entirely by themselves in Rebas. They intermarry only among themselves, so that their peculiarities continue to be reproduced. Entirely without educa. tion, and without any chance of improving their condition, they lead the life of pariahs. They know their own names, but rarely remember those of their parents, can hardly tell where they live, and have no idea of numbers.

\section{JOHN HUNTER}

THE Hunterian Oration was delivered on Monday afternoon in the theatre of the Royal College of Surgeons by the President, Mr. Savory, F.R.S., Senior Surgeon to St. Bartholomew's Hospital. After a few introductory remarks, Mr. Savory proceeded to say that surgeons with one voice have proclaimed the supremacy of Hunter above all who have ever studied surgery. Students of science have acknowledged him to be among the chief of those who have in any age advanced human knowledge. He was, and is, beyond and above all surgeons, a philosopher in surgery. His idea of the subject of his thoughts was far more adequate than that of other men. He was supreme in the scope and method of his work. He understood much better than those around him how to engage in the interpretation of Nature; he knew best how to approach and to disclose truth. For he not only understood that the problems which lay immediately before him were, of all, the most complex and difficult to solve, but he could see also that they were not isolated but dependent ones. He saw in the necessary relation in which they stood to others the only means by which they could be worked out; and on this understanding he resolved to investigate the questions he desired to answer. Mr. Savory next spoke of the passion of Hunter for collecting. His museum included, he said, not only-to use the words of Professor Flower"illustrations of life in all its aspects, in health and in disease specimens of botany, zoology, palæontology, anatomy, physiology, and every branch of pathology ; preparations made accord ing to all the methods then known; stuffed birds, mammals, and reptiles, fossils, dried shells, corals, insects, and plants ; bones and articu'ated skeletons; injected dried and varnished vascular preparations; dried preparation; of hollow viscera, meicurial injections, dried and in spirit ; vermilion injections; dissected preparations in spirit of both vegetable and animal structures, natural and morbid; undissected animals in spirit, showing external form or awaiting leisure for examination; calculi and various animal concretions; even a collection of microscopic objects, prepared by one of the earliest English histologists, W. Hewson ; but it extended to minerals, coins, pictures, ancient coats of mail, weapons of various date; and nations, and other so-called "articles of vertu." "Hunter's labours in surgery were next referred to. He was ever searching for principles, but strove to reach them only through facts. Facts always first, but never facts only; from facts to principles. He understood that all progress mainly depends on the power of grouping and uniting for some new purpose facts that have been discovered independently and that are daily being revealed, yet with little or no reference to the principles they are found to support. He saw that surgery, in his time, was but a rude, empirical art, consisting of little else than a knowledge of many facts which stood in no visible relation to each other, and of many more opinions which, for the most part, had no relation, or but a very distant one; to any facts whatever. He held that surgery should be raised from a collection of such creeds to the rank of a science, but this could be only by founding its practice up $\supset$ some principles. The discovery of some, at least, of these principles was Hunter's final aim. But those principles could not be reached by guessing. They could be approached only through the orderly investigation of facts. But then an explanation of these facts themselves could be only through the truths of physiology. The signs of disease could be understood only by him who had studied the laws of life and health. An intelligent interpretation of the one could be only in proportion to a previous knowled ge of the other. But the problems of life, of health, are presented to us in man in their most complex form-in a form so difficult that even Hunter could not solve it. They must be reduced to simpler terms through a study of the lower forms of life. Thus, with the ultimate aim of relieving human suffering, Hunter studied the phenomena of motion in plants. Nay, he went further, to crystals and other forms of inorganic matter; and he says: "The better to understand animal matter, it is necessary to understand the properties of common matter, in order to see how far these properties are introduced into the vegetable and animal operations." The singleness of purpose with which Hanter worked is made evident, Mr. Savory continued, not only in the actual result of his labours, for no human being with divided interests could rival such achievements, but in the record, as we have it, of the life he led. He gave not only the whole of his time-yes, the whole of it in no mere conventional sense-and all his great powers, his mind and body alike, to the one object of his life ; but to this he sacrificed all that he possessed, all that he could gain. To this he devoted, without stint or scruple, his money, his friendships, all his other interests. What any other man would have considered impossible, he made practicable. And this to no personal end. He was careless of all rewards save that which was to him paramount, the discovery of truth. A noteworthy point in the character of Hunter appears to be found in the relation which, in him, thought bore to action. He com. bined in himself in a singular degree the power of conception and of execution. He not only saw much further, but he was able to do much more than most others. He saw as Bacon saw -and the idea was probably as original with him as with Bacon - that the systematic and thorough examination of facts was the first thing to be done in science, "and that, till this had been done faithfully and im zartially, with all the appliances and all the safeguards that experience and forethought could suggest, all generalisations, all anticipations from mere reasoning, must be adjourned and postponed; and further, that, sought on these conditions, knowledge, certain and fruitful, beyond all that man then imagined, could be obtained." But he went immeasurably further than the great prophet of science in putting his conceptions to the proof in imperishable work on the lines he had laid down. "I only sound the clarion," said Bacon, proudly, "but I enter not into the battle." Hunter sounded a clarion the echoes of which are reverberating still, but he entered into the battle also, and was a'ways found where the blows fell thickest, and we are in possession of the spoils. In his museum there is, at once, the clearest evidence of the idea and the richest fruits of execution. In speaking of Hunter's general education, Mr. Savory proceeded to say that if Hunter had received a good general education in early years he would have been all the better for it. He would have lost nothing. His mental powers could have been in $\mathrm{n}$, way impaired; on the contrary, enhanced. He would have recorded the results of his labours in better order, with more light and greater effect, and we should have had the advantage of a clearer revelation of his thoughts. But all this is very far from saying that Hunter was not, in the strictest sense, an educated man. He was not, indeed, a scholar. If th s subtle rendering of a Greek poet, or the skilful turnin of a Latin verse be the sole test of culture, he gave no sign of it. Of ancient lore he was sadly destitute. In Literis Humanioribus he could have 
had no place. But if a transcendent knowledge of Nature and her ways, if a firm and ample grasp of her noblest truths, be accounted education, if the devotion through a lifetime of gigantic intellectual powers and of a truly loving heart to the reverent study of God's works be culture, then Hunter, though not a man of letters, was surely a highly educated man. The fame of Hunter, after all, falls far short of him. It may, without exaggeration, be said that he is really greater than to most men, even to most surgeons, he appears to be. It is only after a review of the whole of his vast labours, in their mutual relation, not merely after a study of the merits of his numerous papers, each taken by itself, but in an attempt to apprehend the scheme to which all his labours were subservient, that we are in any measure able to realise the strength of Hunter's genius. Then, as the chief merit of his work is not of a character to catch at once the eye, even of one who searches for it, so his subject is not one of widespread or popular interest. Of all men who have achieved greatness, Hunter requires to be studied with most diligence, the more so because of the absence of all literary skill. And there can be no doubt that he shared the fate of all those who have been, like him, in advance of their time. He was so far beyond his contemporaries as to be, for the most part, out of their reach, and therefore they left him alone; and even his successors have not always found him out. It may, indeed, be said to have been almost by an accident that, in association with the possession of his museum, we have periodically a festival in honour of his memory. Such, then, at least in the eyes of one who, though from afar, has long and earnestly looked up to him, was John Hunter. Beyond all cavil, if the word have any meaning for us, he was a man of genius - a man supremely endowed with power and faculties for the discovery of truth. With little education at the outset of life, without the advantage of the schools, he found himself face to face with the deepest and most mysterious problems of Nature, and he was forthwith able to take full measure of the magnitude of the task. It seems never to have occurred to him that he could snatch an answer by surprise; that a solution could be reached by any short or sudden means. But his survey assured him that upon one plan only, but by that abundantly, could success be made certain. So with patience, which of itself has been called genius, he went back to the beginning. It was genius too, and that of the highest order, to discern, at so vast a distance, where the beginning lay. But there he placed himself, and from that point went forward only when he had made each footstep sure. Who shall say that his imagination was not fertile, or that he faltered in the use of it? Yet no seductive theory tempted him into undue haste, and though sometimes drawn aside by a specious speculation, he seems hardly ever to have been lost in an unsound conclusion. And when he fell, the treasures he had won were found not only in the multitude of facts he had garnered, or even in the principles which, by virtue of the facts he had discovered, were made plain, but also in the very plan and purpose of his work. For, from the height on which at length he stood, not only can the path he trod be clearly traced, but the highway thenceforward is disclosed. So is the greatness of John Hunter to be estimated, not only by what he discovered, but rather by the lesson and example of his work. Truly it may be said of him that he did much. Truly it may be said of him that he showed how much more there is to be done. "He being dead yet speaketh," still speaks to us as no other man before or since has spoken. But when and where can his voice be heard most plainly? Are the spirits of those who have shaken off "this muddy vesture of decay" permitted to revisit the scenes of their earthly labours? Can they still be with us on our way? If the soul of this mighty son of science is ever in our midst, surely his favourite haunt must be now within these walls-in the museum which will soon almost surround us, at once his most graphic and glorious monument. The memory of Hunter, like the memory of the greatest men of every age, is imperishably enshrined. Art, in her noblest efforts, has striven to make his form familiar to us. His name is stamped in indelible characters on the records of human progress. But, before all, he lives in, and draws the breath of life from, his own immortal works. And of these none can be so truly a memorial of the very man as this; no other can so resemble him, can possess so much of him, can tell so fully of what he was; can so perpetuate him in the vast store of facts, in the purpose for which they are set forth, in the illustration of principles, in the suggestion of truths beyond those it can show, above those it can reach-in all this, I say, no memorial, however majestic, can rival our museum. The foundation of this with his own hand and his whole heart he laid; it has grown, and still is growing, from his strength, and it must be made for ever worthy of his name.

\section{UNIVERSITY AND EDUCATIONAI INTELLIGENCE}

OXFORD.-The following new Examiners have been appointed in the Natural Science School: Mr. V. H. Veley (Chemistry), Dr. W. H. Gaskell and Prof. Ray Lankester (Biology), Mr. J. V. Jones (Physics). Mr. W. W. Fisher and the Rev. F. J. Smith are to be Examiners in the Pass Schools.

The Sibthorpian Professorship of Rural Economy is now vacant, and canditates for it are requested to send in their applications to the Registrar of the University before March Io.

The Board of the Faculty of Medicine has issued a list of subjects to be offered in the first examination for the B.M. degree under the new medical statutes.

Scholarships in Natural Science are announced for competition at Merton, Corpus, and Queen's, and at New College.

\section{SCIENTIFIC SERIALS}

American Fournal of Science, January.-The Muir glacier, by G. Frederick Wright. The paper contains an exhaustive study of this interesting glacier, which lies in the Alpine region of Alaska at the head of Muir Inlet, Glacier Bay, in $58^{\circ} 50^{\prime} \mathrm{N}$. lat., $\mathrm{I} 36^{\circ} 4 \mathrm{O}^{\prime} \mathrm{W}$. long. It forms a frozen stream some 5000 feet wide by 700 deep, entering the inlet at a mean rate of 40 feet, or $140,000,000$ cubic feet, per day, during the month of August. The vertical front at the water's edge is from 250 to 300 feet, and from this front icebergs are continually breaking away, some many hundred feet long, with a volume of $40,000,000$ cubic feet. The glacier appears to be rapidly retreating, there being indica. tions that even since the beginning of this century it has receded several miles up the inlet, and fallen 1000 or 1500 feet below its former level. - On the age of the coal found in the region traversed by the Rio Grande del Norte, by C. A. White. The carboniferous beds occurring at various points in this region vary greatly in quality, but none of them appear to be earlier than late Cretaceous age.-The viscosity of steel and its relations to temper (continued), by C. Barus and V. Strouhal. Ameng the chief results of the authors' further experiments, as here described and tabulated, is the light thrown on the crucial importance of the physical changes which steel undergoes during annealing at high temperatures between $500^{\circ}$ and $1000^{\circ} \mathrm{C}$. Within these limits occur several nearly coincident phenomena: such as Gore's sudden volume expansion; Tait's sinuously broken thermoelectric resistance ; Gore-Baur's sudden disappearance of magnetic quality; the passage of carbon from uncombined to combined; Jean's critical cementation temperature ; and the authors' own unique maximum of viscosity.--On the nature and origin of lithophysæ, and the lamination of acid lavas, by Joseph P. Iddings. The data upon which the conclusions here stated are based were obtained from a study of the various forms of structure and crystallisation assumed by acid lavas in cooling, as observed while prosecuting the work of the United States Geological Survey in the Yellowstone National Park under Mr. Arnold Hague. The lithophysæ, composed of prismatic quartz, tridymite, soda-orthoclase, fayalite, and magnetite, appear to be of aqueoigneous origin, having been produced by the action of the absorbed gases upon the molten glass from which they were liberated during the crystallisation consequent upon cooling. It also seems highly probable that the differences in consistency and in the phases of crystallisation producing the lamination of this rock were directly due to the amount of vapours absorbed in the various layers of the lava and to their mineralising infuence.The latest volcanic eruption in Northern California, and its peculiar lava, by J. S. Diller. The volcanic district here described is that of the so-called "Cinder Cone," near Snag Lake, North California, where the recent character of the eruptive phenomena is most striking as compared with other outbursts in the same region. The lava field, some three square miles in extent, is of basaltic type, but remarkably anomalous in containing numerous grains of quart $z$, and very high percentages of silica and magnesia with correspondingly low quantities of the oxides of iron. - On the texture of massive rocks, by 